\title{
Review of: "Pre-collisional extension of microcontinental terranes by a subduction pulley"
}

\author{
Vlad Constantin Manea ${ }^{1}$ \\ 1 Universidad Nacional Autónoma de México
}

Potential competing interests: The author(s) declared that no potential competing interests exist.

This research paper examines the state of stress in microcontinental terranes before their collision with a subduction zone, and propose that drifting lithospheric plates undergo substantial tectonic deformation even before the arrival at subduction margins. This study challenges the traditional view, and show that pre-collisional extension can occur within microcontinents that are drifting towards a subduction. Modeling results show that the magnitude of pre-collisional extension is inversely correlated with the size of the microcontinental terrane and convergence velocity. Combining forward geodynamic numerical experiments, kinematic analyses and geothermobarometric data the authors show that the Sesia zone, located in the Swiss and Italian Alps, and Eastern Anatolia, Turkey, show evidence of this style of precollisional extension.

Although this study offers a different view regarding extensional tectonics in microcontinents subject to accretion to an overriding plate, there are a number of problems that need to be addressed in future studies, which include the following:

1. The geodynamic modeling is performed in 2D, therefore only width of the microcontinents is tested. However, it would be helpful to investigate more realistic 3D dynamic models. For example, would be quite noteworthy to show how the other microcontinent dimension (along the strike) influence the stress pattern before collision. Further, as multiple microcontinents might approach a subduction zone (simultaneously of sequentially), 3D modeling would offer a great opportunity to test whether limited in size microcontinents still develop the same stress pattern presented in this work. Additionally, several parameters should be tested as the microcontinent's lengths and sizes, and also the distance between adjacent microcontinents.

2. In this study, microcontinents are considered as uniform (i.e. flat top) and homogeneous tectonic blocks. However, would be interesting to see how surface topography, and/or interior heterogeneities, might influence pre-collisional tectonic stress distribution.

3. Temperature distribution in the oceanic plate is considered to vary linearly with depth (i.e. from $0^{\circ} \mathrm{C}$ to 
$1350^{\circ} \mathrm{C}$ at $70 \mathrm{~km}$ depth). This might eventually correspond to a very old oceanic lithosphere. However, for younger oceanic plates temperature distribution does not var linearly with depth and it is a function of plate age. Is there any plate age dependency for pre-collisional tectonic stresses in these microcontinents?

4. The authors compare modeling results with kinematic analyses and geothermobarometric data from Sesia zone, located in the Swiss and Italian Alps, and Eastern Anatolia, Turkey. However, there are other key regions/settings where testing this newly discovered stress pattern in accreted terranes might bring new insights. Plate tectonic evolution of the Kamchatka-Aleutian junction area shows that Kronotskiy Arc started to impact the proto Kamchatka subduction zone in Late Eocene, and then accreted terranes impinged the margin in a serial manner from south to north (Alexeiev et al., 2006).

5. While the imposed convergence rates in this study vary from 0 to $4 \mathrm{~cm} / \mathrm{yr}$, testing higher rates (i.e. 6 to $10 \mathrm{~cm} / \mathrm{yr}$ ) would shed more light on the tectonic evolution of microcontinents in fast subduction settings.

6. For future studies would be beneficial to extend the modeling duration and investigate if microcontinents accretion is able to jump and restart subduction on the far margin.

\section{References cited}

Alexeiev, D.V., Gaedicke, C., Tsukanov, N.V. et al. Collision of the Kronotskiy arc at the NE Eurasia margin and structural evolution of the Kamchatka-Aleutian junction. Int J Earth Sci (Geol Rundsch) 95, 977-993 (2006). https://doi.org/10.1007/s00531-006-0080-z 